\title{
A facilitating framework for a developing country to adopt smart waste management in the context of circular economy
}

\author{
Feroz Khan ${ }^{1}$ - Yousaf Ali $^{1}$ (1)
}

Received: 1 September 2021 / Accepted: 12 November 2021 / Published online: 1 December 2021

○ The Author(s), under exclusive licence to Springer-Verlag GmbH Germany, part of Springer Nature 2021

\begin{abstract}
To achieve higher standards of sustainability, the waste management sector now requires the incorporation of circular economy (CE) principles. However, an easy transition toward the particular goal would require the use of smart waste technologies. To achieve the aforementioned goal, this study aims to provide a facilitating framework for the adoption of smart waste management in the context of CE for Pakistan. To help Pakistan transition toward the new paradigm, a total of 16 critical facilitators are evaluated based on five distinctive criteria using a novel fuzzy hybrid multi-criteria decision-making (MCDM) approach. The hybrid MCDM approach includes fuzzy Stepwise Weight Assessment Ratio Analysis (SWARA) for allocating weights to the determined criteria; whereas, the fuzzy VIšekriterijumsko kompromisno rangiranje (VIKOR) approach is used to rank the critical facilitators adopted from the secondary literature. The fuzzy approach in both cases is to deal with any kind of uncertainty during the data collection process. Based on the achieved results, the study suggests that before the application of smart waste technologies in the country, Pakistan should first focus on devising regulations that effectively address the mismanagement of waste produced in the country. Also, the industries in the country need to become more responsible and should adopt environmental management systems that foster waste minimization. Lastly, the country in the third phase should focus on the wide application of digitalization both in the streams of ICT and IoT, for collecting, sharing, and receiving waste data. The study further provides policy recommendations to the respective stakeholders that will help the country achieve zero-waste CE.
\end{abstract}

Keywords Waste management $\cdot$ Circular economy $\cdot$ Digitalization $\cdot$ Developing country $\cdot$ Fuzzy $\cdot$ MCDM

\section{Introduction}

Due to the ever-increasing population, there is a significant increase in the generation of solid waste around the world. Solid waste management has become a serious problem not only for developed countries but also for developing nations as well. The term "solid waste management" refers to the collecting, treating, and getting rid of solid waste material that no longer serves any purpose. Problems arise when

Responsible Editor: Philippe Garrigues

Yousaf Ali

yousafkhan@giki.edu.pk

Feroz Khan

gem1970@giki.edu.pk

1 School of Management Sciences, Ghulam Ishaq Khan Institute of Engineering Sciences and Technology, Topi, Swabi, KPK, Pakistan waste is not managed or disposed of in an environmentally safe manner, which as a result creates unsanitary conditions that cause several diseases. Solid waste management is a complex task that poses several challenges in the shape of social, administrative, and economic problems. Currently, the world generates around 2.01 billion tons of municipal solid waste; however, this number is expected to rise to 3.4 billion tons by 2050. In the current 2.01 billion tons of solid waste generated, about $33 \%$ of the waste is not managed in an environmentally safe manner (The World Bank 2019). For effective waste management, technological advancement in the waste management sector started in the early nineteenth century. Initial practices primarily focused on incineration and primordial disposal methods such as open dumping on land or in water. However, due to the negative impact of incineration and landfilling on the environment, modern practices are leaning more toward recycling rather than incineration and land disposal methods ( Nathanson 2020). 
More recent development in waste management incorporate the $\mathrm{CE}$ approach, which gives a rather new perspective to the existing waste management practices. The CE approach primarily works on the $3 \mathrm{R}$ principle, i.e., reduce, reuse, and recycle policy (Ellen MacArthur Foundation 2013). Essentially, the CE approach aims at utilizing resources in the best possible manner to avoid waste and achieve resource efficiency. The particular approach further deals with the recovery of value from waste, aiming to achieve circularity in the usage of resources. In this case, the role of industries becomes really important to adopt business models based on the concepts of the circular and sharing economy. Sustainable waste management practices such as reusing, refurbishing, or recycling can be ensured through reverse logistic infrastructures. However, to aid these processes, the role of industry 4.0 or smart technologies has received considerable attention (Wilts et al. 2021, pp. 1-31). Smart waste technologies are in the streams of the Internetof-Things (IoT), artificial intelligence (AI), and big data (Sarc, Curtis, Kandlbauer, Khodier, Lorber, and Pomberger Digitalisation and intelligent robotics in value chain of circular economy oriented waste management - a review 2019). The application of smart waste management technologies comes under the umbrella of smart cities. The aim of smart cities is to adopt cyberinfrastructure and industry 4.0 technologies to achieve sustainable development, thus, helping to achieve a better quality of life, resource efficiency, and economic growth (Ali et al. 2020). According to the United Nations, digital tools help enable waste management more efficiently. Also, using smart waste management technologies results in the reduction of carbon emissions by about $60 \%$ in cities. (Lenkiewicz 2016).

The inability to track daily waste created in cities and their effective collection and segregation is a challenging task. Furthermore, the municipalities, scavengers, and waste pickers are subjected to serious health risks because of ineffective waste management practices (Zolnikov et al. 2018). Hence, to tackle this issue, smart waste management is the most effective and suitable solution to this problem. Smart technologies in waste management primarily focus on the use of location-based technologies (e.g., GIS and GPS), data gathering technologies (e.g., sensors and imaging), identification-based technologies (e.g., barcodes and RFID), and finally, data transmission technologies (e.g., Bluetooth, Wi-Fi, and GSM). The last three among the abovementioned technologies are given the most attention (Esmaeilian, Wang, Lewis, Duarte, Ratti, and Behdad, The future of waste management in smart and sustainable cities 2018). RFID tags are effectively used for identifying waste, capacity sensors for identifying levels of waste, and actuators to close the bins once they are filled. Whereas, wireless devices are used to send waste data to the control center (Shyam et al. 2017). Among smart waste technologies, smart bins have also got considerable attention. These IoT-enabled smart bins use sensors along with other technologies such as actuators and motors to detect the level of waste along with the identification and segregation of waste (Mittal 2020). Hence, this benefits the municipalities and other organizations on the timely collection of waste. It also optimizes the routes for trucks that collect waste, resulting in fewer greenhouse gas emissions and reduced fuel consumption (Lozano et al. 2018). Several types of smart bins are being developed and are available in the market, each having its own set of properties. For example, there are smart bins that do not only focus on waste levels but also segregate the waste according to its type along with other benefits like eliminating the smell associated with the specific type of waste, etc. (Nižetić, Djilali, Papadopoulos, and Rodrigues, Smart technologies for promotion of energy efficiency, utilization of sustainable resources and waste management 2019). However, smart waste management does not wholly solely depends on the adoption of smart bins but an amalgamation of several smart technologies working together to make the whole process of waste management more effective (Melaré, González, Faceli, and Casadei, Technologies and decision support systems to aid solid-waste 2017).

Solid waste management is a problem more prevalent in developing countries, and a country like Pakistan is no exception. According to an approximate, Pakistan generates around 48.5 million tons of solid waste each year, and there is an increasing rate of $2 \%$ each year (International Trade Administration 2019). The waste management infrastructure in Pakistan is seriously outdated, which creates some serious environmental threats. All the major cities of Pakistan face the same problem especially the metropolitan city Karachi, which produces around 13,500 tons of waste daily. Whereas, the rest of major cities cumulatively produces 87,000 tons of waste daily (International Trade Administration 2019). Due to the lack of administrative, institutional, and financial constraints, there is neither a proper collection nor disposal of municipal solid waste. The collection rate is about $60 \%$, whereas the remaining $40 \%$ is left on the open grounds ( Korai et al. 2020). The uncollected waste as a result poses serious health risks in the form of clogging drains, formation of stagnant forms, which results in providing a breeding ground for mosquitoes and flies, making diseases like malaria and cholera more prevalent. Whereas, the other collected waste is dumped openly into pits, ponds, rivers, and agricultural land (Shah et al. 2019). All of this is because of the lack of standard operating procedures to follow on waste management in the country. For example, lack of infrastructure, proper planning, government's will, and public awareness are some of the contributing factors (Azam et al. 2020).

To solve the abovementioned problems, Pakistan needs to revise and focus on its waste management practices and adopt sustainable smart waste technologies along with the 
principles of CE. However, the transition toward the particular goal would be hindered by regulatory, technical, and economic barriers. These barriers have been outlined and have been studied in the context of emerging countries like China and India, respectively (Zhang et al. 2019; Sharma et al. 2020). However, the literature is silent on providing a supporting framework for the adoption of smart waste management in the context of CE for Pakistan. Every country has its own set of policies and targets to achieve, and so it becomes very essential to formulate a country-specific framework to achieve the desired goal. Furthermore, a country like Pakistan is still in its infant stage when it comes to the concepts of CE. Also, studies based on sustainable smart cities especially in the context of developing countries like Pakistan are still untapped; therefore, the margin of contribution to the literature in the specific domain is quite considerable (Esmaeilian, Wang, Lewis, Duarte, Ratti, and Behdad, The future of waste management in smart and sustainable cities 2018). To facilitate sustainable waste management in Pakistan, the aim of this study is threefold. Firstly, through an extensive literature review, a list of critical facilitators for adopting smart waste management in the context of CE would be finalized with the help of experts. Secondly, a hybrid MCDM technique would be used to evaluate the critical facilitators based on five distinctive criteria, i.e., environmental, social, economic, technical, and regulatory perspectives. Lastly, based on the achieved results, policy recommendations would be given to respective stakeholders in the waste management sector of the country.

The rest of the paper is outlined in such a manner that Sect. 2 will comprise of literature review, followed by data collection and methodology in Sect. 3. Furthermore, Sects. 4 and 5 would include results and discussion and conclusion, respectively.

\section{Literature review}

With the increasing world population, waste management is becoming a challenging task for both developed and developing countries. However, developing countries face more challenges because of meager resources (Asase et al. 2009). The problem further worsens for developing countries because there is a growing $C E$ trend in which recyclable and secondhand materials are exported from developed to developing countries, which as a consequence adds an additional burden on such countries. Therefore, developed countries need to work on their waste minimization and support the developing countries by transferring waste management and recycling technologies (Liu et al. 2008). There are three main stakeholders when it comes to waste management in a country. They include the government (municipalities), industries, and the social community. All these stakeholders need to work in a cohesive environment, where the ultimate aim should be to collaborate and achieve maximum sustainability. The aforementioned goal can be achieved through a cloud-based system, where all the stakeholders can access and receive waste data (Aazam et al. 2016).

The challenges faced by developing countries can be overcome through smart enabling waste technologies. Examples of these smart technologies include the usage of software, electronics, sensors, and actuators for the proficient processing and exchange of data. However, the adoption of these technologies comes with technological and R\&D barriers when it comes to developing countries. Hence, developed countries need to work on collaborating with international researchers to fulfill the lack of local research (Melaré, González, Faceli, and Casadei, Technologies and decision support systems to aid solid-waste management: a systematic review 2017). Furthermore, other social, technical, and regulatory hindrances need to be tackled to effectively transition toward the use of smart waste technologies (Marshall and Farahbakhsh 2013). The usage of smart technologies would bring benefits such as efficient collection, sorting, and segregation of waste, along with abstaining waste pickers, municipality workers, and the general public from various health risks. In addition to this, these technologies would also help in enhancing the process of recovering value from the waste (Ramos et al. 2018), helping in meeting the SDG targets while enabling a more circular-oriented economy (Hannan et al. 2020).

Apart from the numerous benefits associated with the adoption of smart waste management, there are certain barriers faced by some countries. To cater to these barriers, countries like China, have already enacted laws to facilitate the transition toward CE. The supporting legislation law came in 2009, intending to bring resource efficiency, preserve the environment, and achieve sustainable development growth (Yong 2007). However, the country still faces certain barriers in the adoption of new technologies. These barriers are in the shape of regulatory and market pressures, and lack of environmental awareness (Zhang, Venkatesh, Liu, Wan, $\mathrm{Qu}$, and Huisingh, Barriers to smart waste management for a circular economy in China 2019). Developing countries like India are also moving toward the concept of smart cities and the adoption of smart waste management technologies. However, the country faces certain barriers in its earlier phases. These barriers are analyzed through hybrid MCDM techniques involving the total interpretative structural modeling (TISM) approach, the fuzzy MICMAC model, and the DEMATEL method. The top critical barriers evaluated as a result were lack of regulations, standardization, and internet facility (Sharma et al. 2020).

Countries like Indonesia are also moving toward the adoption of smart waste technologies, particularly focusing on the usage of IoT technologies to identify, separate, 
and treat waste. (Fatimah et al. 2020). Adopting smart waste technologies is a step toward building smart cities. The concept of smart cities is still new and challenging to developing countries. To investigate such challenges, a study in the case of India has been conducted where the goal was to provide critical enablers that would help the country achieve its objectives. The critical enablers are ranked using a hybrid MCDM approach consisting of the BWM and ISM for an easy transition toward the building of smart cities. The results of the study suggest sustainable resource management and the development of smart buildings are the topmost enablers (Yadav et al. 2019). There are several factors that affects and influence the transition toward a circularoriented waste management approach. These factors include social, economic, and regulatory indicators that need to be taken into account when devising a supporting framework. The formulation of a supporting framework needs to involve decision-makers and experts where the results should not be based just on theory (Salmenperä, Pitkänen, Kautto, and Saikku, Critical factors for enhancing the circular economy in waste management 2021).

This study aims to focus on the developing country, Pakistan, and how it can adopt the principles of CE through the adoption of smart waste management technologies. Pakistan has a huge potential when it comes to the incorporation of the CE approach in the waste management sector. The wide implementation of $\mathrm{CE}$ principles in waste management would help achieve sustainable development goals in the country (Tariq et al., 2021). However, a joint effort is needed where all the stakeholders including the society have to play their part (Ali et al. 2018a, 2018b). Recent literature on the waste management sector of Pakistan is limited and does not concentrate on the CE trend. A few of these studies include the determination of the most optimal way to manage the waste of the city, Lahore. For this purpose, a hybrid MCDM approach, i.e., fuzzy AHP-TOPSIS, is used to rank the best alternative. The results of which suggest anaerobic digestion to be the best alternative for treating the waste in the city (Ali et al. 2018a, 2018b). Lack of financial resources and data available on the production of waste generation in cities is the biggest problem for the regulatory bodies to devise a proper plan for solid waste management in Pakistan (Ilyas et al. 2017). Open dumping of waste is a serious problem in most of the cities of the country. To tackle this problem, proper supervision and monitoring of waste are very important for effective waste management in the country (Usman et al. 2017). The same problem is also prevalent in the twin cities of Islamabad and Rawalpindi, where ineffective waste management practices are causing several diseases among the people (Akmal and Jamil, Assessing health damages from improper disposal of solid waste in Metropolitan Islamabad-Rawalpindi, Pakistan 2021). In large cities like Karachi, around $70 \%$ of the waste goes to landfills, which causes significant pollution in the city. The city also lacks a proper system for recovering or recycling waste. Therefore, the country requires a proper and effective waste management system in which both the formal and informal sector needs to take part (Aslam et al. 2021).

When it comes to recovering value from waste, most of the recent studies in the context of Pakistan focus on wasteto-energy and incineration technologies (Siddiqi et al. 2019; Shah et al. 2021; Safar et al. 2021). However, the literature is still silent when it comes to the adoption of CE principles through the help of smart enabling technologies in the waste management sector of the country. This study fills in this gap by adopting and evaluating critical facilitators through which the country can engage in more sustainable waste management practices. The critical facilitators are evaluated based on five distinctive criteria, using a fuzzy hybrid MCDM approach. Over the years, several MCDM techniques have been developed and have been used in various studies. These MCDM techniques include TOPSIS, AHP, BWM, MARCOS, EDAS, and FUCOM, etc. Example of such studies includes the evaluation of e-service quality in the airline industry through the fuzzy AHP and MARCOS approach ( Bakır and Atalık 2021). Whereas, the MARCOS methodology has been used in the selection of a supplier for a steelmaking company (Badi and Pamucar 2020). The selection of the most sustainable waste management technique in Nigeria uses the EDAS approach (Muhammad et al. 2021). The application of fuzzy TOPSIS has been seen in the selection of the most sustainable hybrid electric vehicle in the context of a developing country (Khan, Ali, and Khan, Sustainable hybrid electric vehicle selection in the context of a developing country 2020). A similar technique has been further applied in evaluating barriers in the adoption of $\mathrm{CE}$ for food waste management in the context of a developing country (Ali, Jokhio, Dojki, Rehman, Khan, and Salman 2021). Moreover, a combination of FUCOM and fuzzy QFD has been applied in assessing strategies for the enhancement of resilience in the health care sector of a developing country (Khan, Ali, and Pamucar, A new fuzzy FUCOM-QFD approach for evaluating strategies to enhance the resilience of the healthcare sector to combat the COVID-19 pandemic 2021). To deal with uncertainty in the decision-making process, fuzzy logic is used to overcome any ambiguity during the process (Ali et al. 2021a, 2021b). However, the hybrid MCDM approach used in this study for evaluating the critical facilitators is fuzzy SWARA and fuzzy VIKOR. The particular hybrid approach has been considered because of its simplicity and its unique set of advantages which are outlined in the subsequent paragraphs.

For the evaluation of criteria, the study uses fuzzy SWARA because of its unique set of advantages. The technique is widely used where the role of policymakers is of prime importance. Therefore, decision-makers have a key 
role when it comes to allocating weights to the criteria (Keršuliene et al. 2010). The technique proves to be very successful in conditions where policymaking is involved on a top level (Zolfani and Saparauskas, New Application of SWARA Method in Prioritizing Sustainability Assessment Indicators of Energy System, 2013). The significance of the considered methodology is its ability to give more accurate results as compared to other MCDM methods (Vafaeipour et al. 2014). SWARA has been used for determining the weights of the criteria in the railway management model (Vesković et al. 2018). It has been further used for the selection of a sustainable design for household furnishing materials, where the results of SWARA were compared with those of BWM. Where results of the study supported SWARA for achieving more consistent and robust results as compared to the BWM (Zolfani and Chatterjee, Comparative Evaluation of Sustainable Design Based on Step-Wise Weight Assessment Ratio Analysis (SWARA) and Best Worst Method (BWM) Methods: A Perspective on Household Furnishing Materials 2019). The technique has been further used in a renewable energy technology selection problem alongside the MULTIMOORA approach for ranking the alternatives (Maghsoodi et al. 2018). Furthermore, for the selection of a third-party logistic provider, fuzzy SWARA has been used for criteria evaluation along with fuzzy COPRAS for ranking the alternatives (Zarbakhshnia et al. 2018). For an outsourcing provider selection problem, the same approach has been used (Perçin, An integrated fuzzy SWARA and fuzzy AD approach for outsourcing provider selection 2019). Also, for the selection of a logistics center, the same approach has been used alongside with fuzzy Combined Compromise Solution (CoCoSo) method rank the best alternative ( Alptekin et al. 2020).

For ranking the critical facilitator, this study uses the fuzzy VIKOR approach. The particular technique has been selected because of its unique set of advantages. The particular approach is capable of deriving the final ranking by taking both the "maximum group utility of the majority," which is a factor that corresponds to the utility of all relevant criteria. It also takes the minimum "individual regret of the opponent into consideration," which considers all the unsatisfactory criteria. The technique further helps the decision-makers in making irrational decisions based on the consideration of lower and higher performance ratings of viable alternatives (Chang 2014). Its usage in the literature involves its application for the selection of the most sustainable supplier selection for the beef industry (Meksavang et al. 2019). It has been further used for the evaluation of renewable technologies in India (Rani et al. 2019). The technique has also been used in combination with ANP for sustainable supplier selection. Where ANP is used for calculating weights of criteria, and VIKOR is used for ranking the alternatives along with using fuzzy triangular numbers
(Baset et al. 2019). An integrated AHP-VIKOR has been further used for a multi-tier sustainable global supplier selection (Awasthi et al. 2018). Furthermore, for the evaluation of the green performance of the airports, the hybrid BWMVIKOR approach has been used (Kumar, A, and Gupta 2020). Fuzzy VIKOR has been also used in combination with Modified-Safety Improve Risk Assessment (ModifiedSIRA) for environmental assessment of E-waste management in the context of a developing country (Hameed et al. 2020). Further studies on fuzzy VIKOR and its application in waste management include (Kabir 2015; Utrillas, et al. 2015; Gündoğdu et al. 2019). Whereas, studies based on fuzzy SWARA-VIKOR have been used to compute ranking for cloud-based selection problems (Akbarizade and Faghihi 2017). The same approach has been further used for a solar panel selection problem ( Rani et al. 2020).

From the studied literature, it can be derived that Pakistan does not have a sustainable framework incorporating the $\mathrm{CE}$ principles when it comes to the waste management sector. Therefore, the current situation in Pakistan regarding unsustainable waste management practices causes several environmental and health hazards. These practices further result in the loss of valuable waste which can otherwise be reused, refurbished, or recycled. Waste management is a complex and intricate sector; therefore, developing a sustainable framework for the particular sector requires the involvement of all stakeholders. Hence, the role of decision-makers or expert opinion, in this case, becomes really important (Torkayesh et al. 2021). Also, powerful decisionmaking techniques play a significant role when it comes to the evaluation of criteria and alternatives (Mi et al. 2021). To address all the abovementioned targets, this study aims to provide a facilitating framework for a developing country like Pakistan to adopt the CE principles in the waste management sector through the adoption of smart waste technologies. For this purpose, the study evaluates the critical facilitators to achieve the aforementioned goal through a fuzzy hybrid MCDM approach involving fuzzy SWARA and fuzzy VIKOR. The fuzzy logic in both cases is used to avoid or remove any kind of uncertainty in the decisionmaking process.

\section{Data collection and methodology}

The methodology developed involves several processes and steps that have been outlined in the flowchart in the shape of Fig. 1 below.

The data collection process involved both primary and secondary data. The first step of data collection involved secondary data, i.e., through an extensive literature review a total of 26 critical facilitators (alternatives) to the adoption of smart waste management in the CE, were 
Fig. 1 Hierarchy of the developed methodology

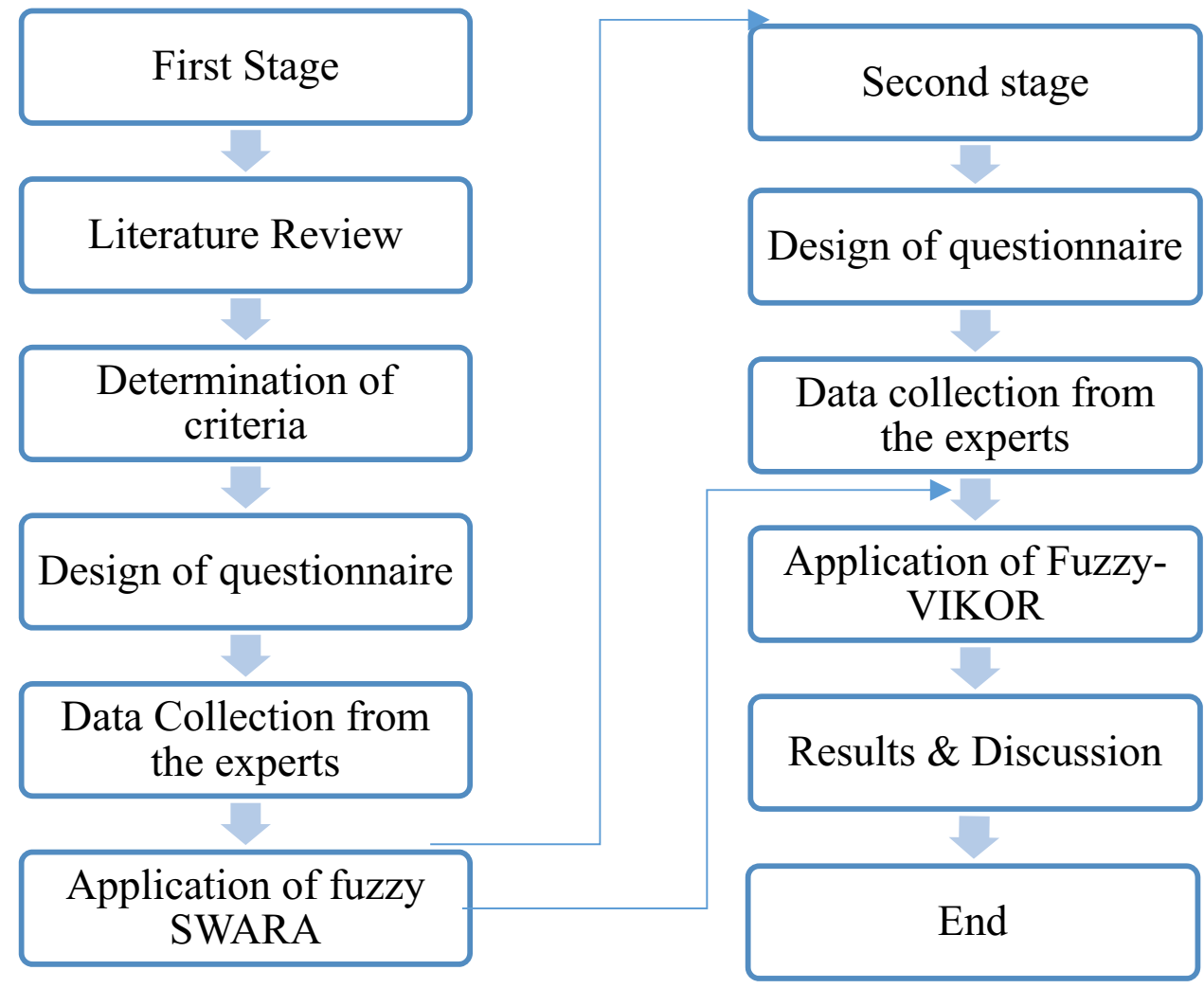

determined. Thereafter, this number was further decreased to a final list of 16 critical facilitators through the help of experts. The role of the experts was to identify the most important facilitators and help remove the redundancy in the overall list. The list of finalized 16 critical facilitators is given in Table 1 below.

The next step in the data collection process was to collect data from the experts to rank the most critical facilitators based on their experience. The 16 facilitators were ranked based on five criteria that include (C1) environmental, (C2) social, (C3) economic, (C4) technical, and (C5) regulatory perspectives. A total of 33 experts took part in the survey. The average experience of the respondents was 10 years. Whereas, the expertise and the respective number of the respondents are summarized in Table 2 below.

A five-point Likert scale ranging from very low to very high was used to collect data from the experts. Using the fuzzy set theory, the linguistic variables were transformed in their respective fuzzy numbers. The particular theory was devised by Lotfi Asgerzadeh from the University of California in 1965 (Zadeh 1965). It is used to capture the vagueness involved when collecting data from the respondents. To allocate numbers to the linguistic variables, Asgarzadeh came up with a set of numbers ranging between $[0,1]$, all having nonnegative numbers.
For example, if $C$ is a reference set having members belonging to $(y)$, then the fuzzy set of $A$ is shown with the help of the following equation:

$C=\{(y, \mu c(y)) \mid y \in A$

The membership function $(y)$ belonging to $(C)$ shows the degree of membership, as to how much $(y)$ belongs to the fuzzy set of $(C)$.

There are various shapes in fuzzy numbers, e.g., bell form, triangular, trapezoid, etc., but here, triangular fuzzy numbers will be used because of their simplicity. The triangular fuzzy numbers have three distance boundaries, i.e., lower, mean, and upper bound. The three variables $(x, y$, and $z$ ) along with the associated triangular shape is given in Fig. 2 below.

The membership associated with the fuzzy numbers is given in Eq. (2) below.

$\mu_{\mathrm{c}}(\mathrm{y})=\left\{\begin{array}{c}y-a / b-a a \leq y \leq g \\ c-y / c-b b \leq y \leq c \\ 0 \text { otherwise }\end{array}\right.$

Here $f, g$, and $h$ are nonnegative numbers in the order of $a<b<c$. The value of $y$ at $f$ gives the maximum value, i.e., $\mu_{\mathrm{c}}(y)=1$; whereas, the value of $y$ at $h$ gives us the minimal 
Table 1 List of critical facilitators for the adoption of smart waste management in the CE

\begin{tabular}{|c|c|}
\hline S.no & Critical facilitators \\
\hline 1 & Business models based on circular and sharing economy concepts \\
\hline 2 & Supportive government policies \\
\hline 3 & Standard operating procedures to follow on waste management \\
\hline 4 & $\begin{array}{l}\text { Educating and spreading awareness campaigns on circular economy } \\
\text { and smart waste management }\end{array}$ \\
\hline 5 & $\begin{array}{l}\text { Transfer of waste for reutilization through an industrial symbiosis } \\
\text { network }\end{array}$ \\
\hline 6 & $\begin{array}{l}\text { Wide application of digitalization for collecting, sharing, and } \\
\text { receiving waste data }\end{array}$ \\
\hline 7 & Incentivizing the procurement of smart waste technologies \\
\hline 8 & Meeting society's expectations for corporate social responsibility \\
\hline 9 & Environmental management systems \\
\hline 10 & $\begin{array}{l}\text { Usage of appropriate methods or technologies to recover value from } \\
\text { the waste }\end{array}$ \\
\hline 11 & An advanced research and development system \\
\hline 12 & $\begin{array}{l}\text { Enhanced citizen participation and green behavior through reward- } \\
\text { based systems }\end{array}$ \\
\hline 13 & $\begin{array}{l}\text { Smooth and uninterrupted internet facility and a strong cybersecu- } \\
\text { rity system }\end{array}$ \\
\hline 14 & $\begin{array}{l}\text { Business opportunities and a potential market for introducing smart } \\
\text { waste technologies }\end{array}$ \\
\hline 15 & $\begin{array}{l}\text { Public-private partnership programs for smart waste technologies } \\
\text { adoption }\end{array}$ \\
\hline 16 & Foreign aid and NGO's involvement \\
\hline
\end{tabular}

References

(Henry et al. 2021; Jabłoński and Jabłoński 2020; Schwanholz and Leipold 2020)

(Ferronato et al. 2019; Avdiushchenko and Zając 2019; Fedotkina et al. 2019)

(AdeolaIdowu et al. 2019; Blaisi 2019; Bui et al. 2020)

(Hartley et al. 2020; Vanapalli et al. 2021; Smol et al. 2020)

(Baldassarre et al. 2019; Abreu and Ceglia 2018; Ali et al. 2019a, 2019b, 2019c)

(Nižetić et al. 2019; Esmaeilian et al. 2018b, 2018a; Shyam et al. 2017; Chaudhari and Bhole 2018)

(Zhang 2019; Ranchordás, 2020; Vohra et al. 2020)

(Daú et al. 2019; Fortunati et al. 2020; Rashid 2020)

(Ikram et al. 2019; Papagiannakis et al. 2019)

(Wainaina et al. 2020; Covidou et al. 2017; Quina et al. 2018)

(Škrinjarić 2020; Cambier et al. 2020; Dipak and Aithal 2021))

(Cardullo and Kitchin 2019a, 2019b; Kumar et al. 2020a, 2020b; Fetanat et al. 2019))

(Kumar et al. 2020a, 2020b; Yadav et al. 2019; Ahad et al. 2020)

(Fatimah et al. 2020; Nižetić et al. 2019; Appio et al. 2019))

(Bao et al. 2019; Yuan et al. 2020; Dolla and Laishram 2020)

(Ferronato et al. 2019; Fedotkina et al. 2019; (Yong et al. 2019)

Table 2 Experts' profile and their number

\begin{tabular}{ll}
\hline Experts & Number \\
\hline Environmental engineers & 7 \\
Municipality officials & 9 \\
Policymakers from the government & 6 \\
Supply chain and logistics managers from companies & 6 \\
Academia (researchers) & 5 \\
Total & $\mathbf{3 3}$ \\
\hline
\end{tabular}

value, i.e., $\mu_{\mathrm{c}}(y)=0$. The constants $f$ and $h$ show the fuzziness of the data. The lesser the distance between the two intervals, the lesser there is fuzziness associated with the data. The ratings associated with the linguistic variables used in this study are shown in Table 3 below.

If there are two triangular numbers such that $\alpha=f, g, h$ and $\beta=f, g, h$, then the distance between the two variables is given with the help of Eq. 3 below.

$d(\alpha, \beta)=\sqrt{\left(\frac{1}{3}\right)\left[f-f^{\prime}\right]^{2}+\left[g-g^{\prime}\right]^{2}+\left[h-h^{\prime}\right]^{2}}$
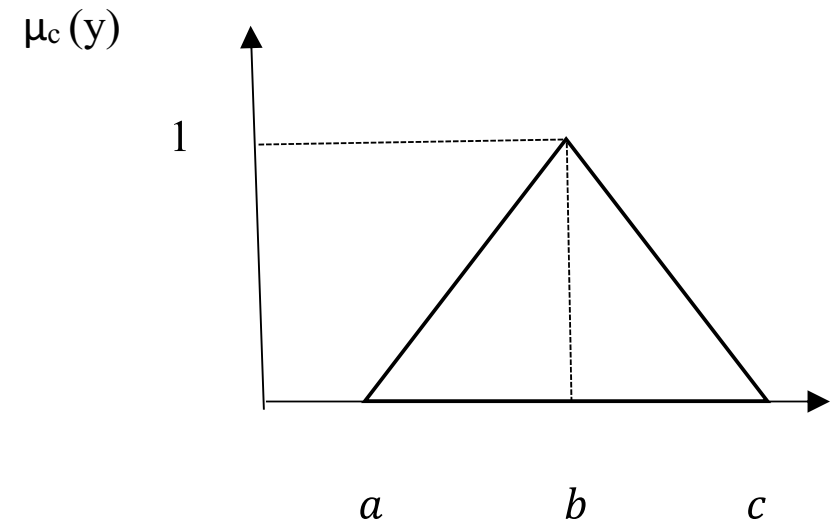

Fig. 2 Triangular numbers

The mathematical equations for dealing with the fuzzy triangular numbers are as follows.

If $A=(x 1, y 1, z 1)$ and $B=(x 2, y 2, z 2)$ are two fuzzy numbers then,

fuzzy addition:

$A+B=(x 1+x 2, y 1+y 2, z 1+z 2)$ 
Table 3 Linguistic variables and their corresponding ratings (source: (Khan, Ali, and Khan, Sustainable hybrid electric vehicle selection in the context of a developing country 2020))

\begin{tabular}{ll}
\hline Linguistic variables & Fuzzy number \\
\hline Very low (VL) & $(1,1,3)$ \\
Low (L) & $(1,3,5)$ \\
Medium (M) & $(3,5,7)$ \\
High (H) & $(5,7,9)$ \\
Very high (VH) & $(7,9,9)$ \\
\hline
\end{tabular}

fuzzy multiplication:

$A \times B=(x 1 \times x 2, y 1 \times y 2, z 1 \times z 2)$

fuzzy division:

$\frac{A}{B}=\left(\frac{x 1}{z 2}, \frac{y 1}{y 2}, \frac{z 1}{x 2}\right)$

After transforming the linguistic variables into their respective fuzzy triangular numbers, the MCDM technique, i.e., fuzzy SWARA, was used to assess the weights of the five criteria. The SWARA technique has been developed by Violeta Keršulienè (Keršuliene et al. 2010). Decision-makers play a pivotal role in evaluating weights to the determined criteria using their expertise and experience. The criteria that receive the significance are ranked first; whereas, the one having the least importance is ranked last. The significance of this method is its simplicity and the benefit of acquiring consistent and robust results (Vafaeipour et al. 2014). The steps associated with the technique are given below (Perçin, An integrated fuzzy SWARA and fuzzy AD approach for outsourcing provider selection, 2019).

Step 1: In the first step, the decision-makers are asked to prioritize the given criteria to the best of their knowledge by using the linguistic variables given in Table 1 . Thereafter, the evaluated criteria are sorted in descending order in the expected order of its significance.

Step 2: In this step, the calculations of the average criterion values is carried out by finding $t_{j}$ :

$t_{j}=\frac{\sum_{k=1}^{r} t_{j k}}{r}$

Where $t_{j k}$ represents the ranking of jth criteria by the kth respondent; also, $r$ shows the number of respondents.

Step 3: In this step, the comparative importance of the sorting criteria is determined based on the expert's opinion which is denoted by $S_{j}$.
Step 4: This step involves the calculation of coefficient value $k_{j}$.

$k_{j}=\left\{\begin{array}{c}1, j=1 \\ s j+1, j>1\end{array}\right.$

Step 5: This step involves the determination of fuzzy recalculated weights represented by $w_{j}$.

$q_{j}=\left\{\begin{array}{c}1, j=1 \\ \frac{x_{j-1}}{k_{j}}, j>1\end{array}\right.$

Step 6: The final step deals with the calculation of fuzzy relative weights of criteria.

$w_{j}=\frac{q_{j}}{\sum_{k=1}^{n} q_{j}}$

The second step of methodology deals with evaluating the alternatives by using the MCDM technique, i.e., fuzzy VIKOR. Here, the weights of the criteria derived with the help of the fuzzy SWARA methodology were incorporated in the fuzzy VIKOR methodology for further evaluation of the alternatives. The VIKOR methodology has been formulated by (Opricovic and Tzeng 2007). The particular methodology helps in finding a compromised solution along with giving a positive and negative ranking of the alternatives with the help of decision-makers. The steps associated with the technique are as follows.

Step 1: The first step associated with the technique is to gather responses from the decision-makers. The survey form is constructed which is filled by a " $q$ " number of decision-makers, who are asked to evaluate the alternatives $\left(S_{k}, k=1 \ldots, m\right)$ based on a given set of criteria $\left(W_{i}\right.$, $I=1 \ldots, n)$.

Step 2: The decision-makers allocate weights to the criteria in accordance with the given set of alternatives. For this purpose, the scale given in Table 1 was used.

Step 3: The following Eq. 11 shows the Fuzzy Decision Matrix (FDM) constructed with the help of responses collected from the decision-makers.

$\mathrm{FDM}=\left[\begin{array}{cccc}x_{11} & x_{12} & \ldots & x_{1 r} \\ \vdots & \vdots & \ddots & \vdots \\ x_{q 1} & x_{q 2} & \ldots & x_{q r}\end{array}\right]$

For $i=1,2,3 \ldots u$ and $j=1,2,3 \ldots v$.

Here $x_{i j}$ is the weights allocated to alternative $A_{i}$ in accordance with the criterion $C_{j}$ by decision-makers.

Step 4: This step involves the determination of fuzzy best values and fuzzy worst values. The following Eqs. 12 and 13 below give the corresponding values, respectively. 


$$
\begin{aligned}
& f_{j}^{*}=\max _{i} x_{i j} \\
& f_{j}^{-}=\min _{i} x_{i j}
\end{aligned}
$$

Here $f_{j}^{*}=\left(f_{j a}^{*}, f_{j b}^{*}, f_{j c}^{*}\right), f_{j}^{-}=\left(f_{j a}^{-}, f_{j b}^{-}, f_{j c}^{-}\right)$

Where $f_{j}^{*}$ refers to fuzzy best values and $f_{j}^{-}$refers to fuzzy worst values.

Step 5: This step involves the determination of $S_{i}$ and $R_{i}$ values with the help of Eqs. 14 and 15, respectively.

$$
\begin{aligned}
& S_{i}=\sum_{j=1}^{v} w_{j} * \frac{\left(f_{j}^{*}-x_{i j}\right)}{\left(f_{j}^{*}-f_{j}^{-}\right)} \\
& R_{i}=\max _{j}\left[w_{j} * \frac{\left(f_{j}^{*}-x_{i j}\right)}{\left(f_{j}^{*}-f_{j}^{-}\right)}\right.
\end{aligned}
$$

where $\left(S_{i}=S_{i a}, S_{i b}, S_{i c}\right)$ and $\left(R_{i}=R_{i a}, R_{i b}, R_{i c}\right)$ and $w_{j}$ refers to the weights of criteria derived from fuzzy SWARA analysis.

Step 6: This step involves the determination of $Q_{i}$ values with the help of Eq. 16 for all alternatives.

$Q_{i}=\frac{v\left(S_{i}-S^{*}\right)}{\left(S^{-}-S^{*}\right)}+\frac{(1-v)\left(R-R^{*}\right)}{\left(R^{-}-R^{*}\right)}$

where $\left(Q_{1}=Q_{a}, Q_{b}, Q_{c}\right)$ and.

$S^{*}=\min _{i} S_{i j}, S^{-}=\max _{i} S_{i j}$

$R^{*}=\min _{i} R_{i j}, R^{-}=\max _{i} R_{i j}$

$\mathrm{S}$ i m i 1 a r $1 \mathrm{y}$

Here, $S^{*}$ indicates maximum group utility, whereas $R^{*}$ indicates the minimum individual regret of the opponent. Thus, both of these elements help in the determination of the $Q_{i}$ index. Furthermore, the variable "v" indicates the weight of the strategy of maximum group utility. Hence, if $v>0.5$, the decision leans toward the maximum group utility; whereas if $v=0.5$, the decision leans toward the minimum individual regret.

Step 7: This step involves the defuzzification of $Q$ values and the ranking. Hence, the triangular fuzzy numbers of $Q$ are defuzzified, and so the alternatives are ranked accordingly. For defuzzification, the geometric mean formula has been used with the help of Eq. 17 below.

$Q_{\text {defuzzified }}=\left(Q_{a}, Q_{b}, Q_{c}\right)^{\frac{1}{3}}$

\section{Results and discussion}

The first step of the analysis dealt with the application of fuzzy SWARA to determine the fuzzy weights of the five distinctive criteria. After the assessment of criteria by experts, the resultant linguistic variables are then transformed into their respective fuzzy numbers using the fuzzy set theory. The first step associated with the fuzzy SWARA methodology was to find the average values of the criteria and sort them in descending order using Eq. 7. Next, the comparative importance of criteria is determined with the help of the expert opinion, which is denoted by $S_{j}$. The next step involves the calculation of coefficient value, denoted by $k_{j}$, using Eq. 8. Similarly, the fuzzy recalculated weights of criteria are found with the help of Eq. 9. The final step associated with fuzzy SWARA is the calculation of fuzzy relative weights using Eq. 10. The results of the analysis are given with the help of Table 4 below.

As evident from Table 4, environmental criteria (C1) have been given the most significance out of all the criteria, by receiving a final weight of $(0.8529,0.8891,0.8980)$. The environment is the most important criterion when it comes to the adoption of CE principles in the waste management sector. Due to the ever-increasing global warming and increase in GHG emissions, environmental sustainability is being considered to be the topmost important factor when it comes to the achievement of UN sustainable development goals and the principles of CE (Adami and Schiavon 2021). It has become even more important in the case of developing countries like Pakistan where poor waste management practices lead to several environmental and health degradation. The biggest example of poor air index quality is Lahore, where people are subjected to several complicated respiratory diseases (Ashraf et al. 2019). To solve the aforementioned problem, the reduction of industrial waste can be the biggest driver toward reduced environmental degradation in the country (Ali et al. 2019a, 2019b, 2019c). The CE approach itself focuses on the adoption of principles that revolve around the use of resources in the best possible manner along with the achievement of goals that revolve around reduced environmental degradation. The aforementioned argument is also advocated by the Ellen Macarthur organization (Haupt and Hellweg 2019).

The next step of the analysis involves the utilization of the weights of criteria obtained from fuzzy SWARA into fuzzy VIKOR for ranking the critical facilitators (alternatives). The first step associated with fuzzy VIKOR is to construct a decision matrix with the help of the responses collected from the experts using Eq. 11. The next step involves the calculation of fuzzy best and worst values using Eqs. 12 and 13 , respectively. Subsequently, this is followed by determining the $S_{i}$ and $R_{i}$ values using Eqs. 14 and 15, respectively. Whereas, Eq. 16 helps with finding the $Q_{i}$ values for all the alternatives. The final step involves the defuzzification of the $Q_{i}$ values using Eq. 17. The results of fuzzy VIKOR containing $Q_{i}$ values and the ranking are given in Table 5 below.

From Table 5, it is evident that the most critical facilitator for effective waste management in the $\mathrm{CE}$ perspective is "standard operating procedures to follow on waste management." There is a significant lacking of a proper plan 
Table 4 Results achieved through fuzzy SWARA

\begin{tabular}{lllll}
\hline Criteria & $\begin{array}{l}\text { Comparative importance } \\
\text { of average values } \boldsymbol{S}_{\mathbf{j}}\end{array}$ & Coefficient $\mathbf{K j}=\mathbf{1}+\boldsymbol{S}_{\mathbf{j}}$ & Recalculated weight $\boldsymbol{q}_{j}=\frac{\boldsymbol{x}_{\boldsymbol{j}-1}}{\boldsymbol{k}_{j}}$ & $\begin{array}{l}\text { Final weight } \\
w_{j}=\frac{q_{j}}{\sum_{k=1}^{n} q_{j}}\end{array}$ \\
\hline C1. Environmental & - & $(1,1,1)$ & $(1,1,1)$ & $(0.8529,0.8891,0.8980)$ \\
C5. Regulatory & $(6.515,8.515,9)$ & $(7.515,9.515,10)$ & $(0.100,0.105,0.133)$ & $(0.0853,0.0934,0.1195)$ \\
C4. Technical & $(3.364,5.364,7.364)$ & $(4.364,6.364,8.364)$ & $(0.012,0.017,0.030)$ & $0.0102,0.0147,0.0274)$ \\
C3. Economic & $(2.939,4.879,6.879)$ & $(3.939,5.879,7.879)$ & $(0.002,0.000,0.001)$ & $(0.0013,0.0025,0.0070)$ \\
C2. Social & $(5.788,7.788,8.939)$ & $(6.788,8.788,9.939)$ & $(0.0002,0.0003,0.0011)$ & $(0.0001,0.0003,0.0010)$ \\
\hline
\end{tabular}

Table 5 Ranked critical facilitators through fuzzy VIKOR

\begin{tabular}{lll}
\hline Critical facilitators & Qi values & Rank \\
\hline Standard operating procedures to follow on waste management & 0.0000 & 1 \\
Environmental management system & 0.0228 & 2 \\
Wide application of digitalization for collecting, sharing, and receiving waste data & 0.1614 & 3 \\
Usage of appropriate methods or technologies to recover value from the waste & 0.1891 & 4 \\
Supportive government policies & 0.2130 & 5 \\
Business models based on circular and sharing economy concepts & 0.2136 & 6 \\
Transfer of waste for reutilization through an industrial symbiosis network & 0.2239 & 7 \\
Incentivizing the procurement of smart waste technologies & 0.3332 & 8 \\
An advanced research and development system & 0.3403 & 9 \\
Educating and spreading awareness campaigns on circular economy and smart waste & 0.4250 & 10 \\
management practices & & \\
Business opportunities and a potential market for introducing smart waste technologies & 0.6765 & 11 \\
Enhanced citizen participation and green behavior through reward-based systems & 0.6852 & 12 \\
Public-private partnership programs for smart waste technologies adoption & 0.7219 & 13 \\
Smooth and uninterrupted internet facility and a strong cybersecurity system & 0.8634 & 14 \\
Foreign aid and NGO's involvement & 0.9028 & 15 \\
Meeting society's expectations for corporate social responsibility & 0.9141 & 16 \\
\hline
\end{tabular}

for effectively managing solid waste in Pakistan. The contributing reasons for the backwardness of effective waste management are the lack of well-trained professionals, financial resources, political will, and technological innovations. Much of the waste produced is uncollected and the rest of which is collected is dumped or burned openly (Akmal and Jamil, Assessing Health Damages from Improper Disposal of Solid Waste in Metropolitan Islamabad-Rawalpindi, Pakistan 2021). The uncollected waste along with the open dumping and burning of waste, as a result, leads to an increase in GHG emissions and pollution in the environment. Also, the untimely collection of waste in the cities further poses a hindrance toward the treatment or recovery of value from the waste (Azam et al. 2020). However, a more circular-oriented approach here would be to focus more on reducing, reusing, refurbishing, and recycling waste where possible. This as a result will not only limit GHG emissions but will also result in the usage of valuable resources in the best possible manner. If any of the abovementioned objectives are not achievable then the second alternative is to incinerate waste for energy recovery (Devadoss et al. 2021). Solid waste has a considerable potential to produce energy in Pakistan. Around $70 \%$ of the imported energy can be avoided through biochemical processes. Whereas, the importing of energy can be completely avoided through the thermochemical processes (Korai, Mahar, and Uqaili, The feasibility of municipal solid waste for energy generation and its existing management practices in Pakistan 2017). The recycling of solid waste can be further increased through energy recovering technologies such as anaerobic digestion, material recovery facilities, and the gasification processes. The particular technology has the potential of giving the highest social, economic and environmental benefits. However, to achieve the aforementioned targets, the government and the municipalities have a huge part to play. The local governments have to make sure, the devised set of operating procedures are followed by both the municipalities and the industries. Here, educating the municipality officials and employees regarding new practices and principles is very important. The specific kind of training can be achieved through giving workshops 
to these workers, along with educating them on smart waste technologies and new recycling technologies.

The second most critical facilitator for effective waste management in Pakistan is "environmental management systems." Industries in any country are responsible for most of the production of toxic and nontoxic waste. Thus, to effectively manage this waste, the industries in Pakistan needs to primarily focus on adopting business models, based on sharing and CE concepts. To minimize waste in the production phase, the industries have to adopt the principles of lean manufacturing. Moreover, a proper analysis of the overall production process can be carried out through performing life cycle assessments. Hence, this is a result would help the industries to achieve sustainable growth along with achieving the CSR targets. The waste produced in the production process can be transferred to other industries for its further usage through an industrial symbiotic network. The waste that is produced in the downstream part of the supply chain can be managed through a reverse logistics infrastructure. For tracking the waste, the usage of RFID tags can be really helpful. The integration of RFID tags, alongside GPS, GPRS, and GIS technologies has proven to be very successful in overall waste collection, bin, and truck monitoring in Malaysia (Hannan et al. 2011). Moreover, the implementation and adoption of certifications like ISO 14001 can further help these organizations to fulfill the CSR objectives alongside the achievement of sustainable development. Here, the government can play its part by making sure these industries are following the right practices by devising supporting policies and legislation. When it comes to the manufacturing industry sector of Pakistan, the organization's culture and control system contribute significantly toward environmental performance (Ong et al. 2019). This in a way would help Pakistan's industries not only to achieve their corporate social responsibility or UN sustainable development goals but would also help these organizations in growing financially. However, sustainable waste management practices can only be followed by industries in Pakistan, if the governing and regulating bodies in the country are more effective in their law-making processes and also ensure their effective application. Unfortunately, the country lacks in both departments (Khan et al. 2021a, 2021b).

From Table 5, the experts ranked the "wide application of digitalization for collecting, sharing, and receiving waste data" to be the third most critical facilitator for effective waste management in the context of CE. The biggest problem associated with developing countries like Pakistan is the lack of availability of waste data associated with the waste generated in the country (Masood et al. 2014). Access to this waste data for all the stakeholders is very necessary for its timely collection and treatment purposes. The aforementioned objective can be attained through the adoption and application of IoT and ICT technologies. The waste data can be made available to all the stakeholders through a cloud-based computing system, helping them to monitor and manage waste data accordingly (Pardini et al. 2020). Moreover, the usage of GIS technology to track and collect waste can be helpful for municipality officials in the timely collection of waste. The usage of the particular technology for efficient monitoring and effective vehicle activity and waste collection has already been proposed to be very beneficial for one of the biggest provinces of Pakistan, i.e., Punjab (Nasir et al. 2017). A study carried out in the case of twin cities, i.e., Islamabad and Rawalpindi, suggests that the application of the GIS technology has the potential to reduce travel time, which was reduced by up to $18 \%$ for Islamabad and 9\% for Rawalpindi. The collection time of the waste was also reduced accordingly (Hina et al. 2020). A lot of financial resources annually go to the collection of waste from the municipal waste bins. It has been seen that adopting IoT-based technologies particularly the use of smart sensors and smart bins can reduce the overall cost of waste collection by $30-40 \%$ (Cassady 2018). It has been studied that the adoption of IoT-based technologies in Pakistan can prove to be very beneficial for the timely collection and treatment of household waste and also waste on a district level (Shaukat et al. 2019). Moreover, adopting smart technologies has a significant potential of achieving social, environmental, and economic targets in waste management and is a driving force toward the achievement of CE principles (Lu et al. 2020; Alcayaga et al. 2019).

All of the above can be made possible through a collaborative framework between all the stakeholders. Without an integrated framework, the transition toward smart management technologies cannot be practical. Thus, the government needs to come up with supporting legislation that is in line with the sharing and CE concepts. The governing bodies need to focus on allocating more budget for waste management. Also, focusing on capacity building of the municipality employees and workers is very essential. The potential investment in waste management and the building of smart cities through the China-Pakistan Economic Corridor project (CPEC) can prove to be very successful toward the adoption of new smart waste technologies (Korai et al. 2020). The public needs to adopt green behavior and should properly dump their waste. Here, incentivizing the public on green practices can be very helpful. Finally, a country like Pakistan is already moving toward the building of smart cities in the cities of Lahore, Quetta, and Multan cities (Farooq 2018). Hence, there is going to be an increasing demand for new smart waste technologies in the country. Thus, this is another enabler for the successful adoption of smart waste management technologies in the country along with bringing potential business opportunities for the people. 


\section{Conclusion}

With each passing year, solid waste management is becoming more complex and difficult to manage because of the increase in the world population. To engage in a more sustainable waste management approach, most countries around the world are moving toward the adoption of CE principles. The aim of this paradigm shift is to engage people and industries into becoming more responsible by reducing, reusing, and recycling waste. However, the transition toward sustainable waste management practices in the accordance with the CE paradigm is not an easy task. In particular, developing countries like Pakistan faces more challenges in their waste management sector because of their meager resources and relatively weak infrastructure as compared to those in developing countries. However, this could be made possible if the country engages in being more responsible in terms of formulating new policies that go in accordance with the CE approach. The intricate nature and the involvement of several whole processes during waste management can be better tackled by adopting new smart waste technologies. However, to achieve this goal, the country has to devise supporting policies and strategies to aid this transition. To solve this problem, the aim of this is to devise a facilitating framework by which Pakistan can adopt sustainable waste management practices in accordance with the $\mathrm{CE}$ approach through the adoption of smart waste management technologies. For this purpose, the study goes through an extensive literature review and identifies 16 critical facilitators with the help of experts for the successful transition toward the new paradigm. These 16 critical facilitators are then ranked based on five distinctive criteria that include environmental, social, economic, technical, and regulatory perspectives. To evaluate the determined critical facilitators, the study uses a hybrid MCDM approach. For the determination of weights of criteria, the fuzzy SWARA approach is used. Whereas, the fuzzy VIKOR approach is used for ranking the critical facilitators. The fuzzy approach used in both cases is to avoid any type of uncertainty during the decision-making process.

Through the application of fuzzy SWARA, the experts prioritized "environmental" criteria to be the most important factor in assessing the critical facilitators. Among the 16 critical facilitators, the experts advocated that Pakistan in the first phase should focus on devising policies and legislation that better addresses the mismanagement of waste in the country. The newly developed policies should be more in line with the principles of CE. The experts on a second priority advocate the adoption of environmental management systems by the industries as the second most critical facilitator toward sustainable waste management practices in the country. In the third phase, the country should move toward the adoption of smart waste technologies for collecting, sharing, and receiving waste data accordingly.

The study suggests that a collaborative and synergetic framework between the municipalities, public, and the industries is very important for a smooth transition toward the principles of $\mathrm{CE}$ and the adoption of smart waste technologies. In essence, supporting policies from the government in this context is also very essential. Furthermore, when it comes to CE, waste minimization and the usage of sustainable technologies to recover value from the waste is also very important. Further studies in this context should focus more on the feasibility of the showcased model in this study by performing a life cycle assessment and cost-benefit analysis of adopting smart waste technologies in Pakistan.

Author contribution All authors contributed to every part of the manuscript. Feroz Khan contributed to the data collection and analysis part, while Yousaf Ali drafted the whole document.

Availability of data and materials Data will be available upon request.

\section{Declarations}

Ethics approval We declare that this manuscript is original, has not been published before, and is not currently being considered for publication elsewhere.

Consent to participate Informed consent was obtained from all individual participants included in the study.

Consent for publication I, the undersigned, give my consent for the publication of identifiable details, which can include data, figures and tables, and details within the text ("Material") to be published in this article.

Conflict of interest The authors declare no competing interests.

\section{References}

Aazam M, St-Hilaire M, Lung C-H, Lambadaris I (2016) Cloud-based smart waste management for smart cities. 2016 IEEE 21st International Workshop on Computer Aided Modelling and Design of Communication Links and Networks (CAMAD), pp 188-193

Adami L, Schiavon M (2021) From circular economy to circular ecology: a review on the solution of environmental problems through circular waste management approaches. Sustainability 13(2):925

AdeolaIdowu I, Atherton W, Hashim K, Kot P, Alkhaddar R, IbitayoAlo B et al (2019) An analyses of the status of landfill classification systems in developing countries: Sub Saharan Africa landfill experiences. Waste Management 87:761-771

Ahad MA, Paiva S, Tripathi G, Feroz N (2020) Enabling technologies and sustainable smart cities. Sustainable Cities and Society 61:102301

Akbarizade Z, Faghihi M (2017) Ranking cloud service providers using SWARA and VIKOR (a case of Irancell Company). Internation 
Journal of Information, Security and Systems Management 6(2):679-686

Akmal T, Jamil F (2021a) Assessing health damages from improper disposal of solid waste in metropolitan Islamabad-Rawalpindi, Pakistan. Sustainability 30(5):2717

Akmal T, Jamil F (2021b) Assessing health damages from improper disposal of solid waste in metropolitan Islamabad-Rawalpindi Pakistan. Sustainability 13(5):2717

Alcayaga A, Wiener M, Hansen EG (2019) Towards a framework of smart-circular systems: an integrative literature review. J Clean Prod 221:622-634

Ali AK, Wang Y, Alvarado JL (2019a) Facilitating industrial symbiosis to achieve circular economy using value-added by design: a case study in transforming the automobile industry sheet metal wasteflow into Voronoi facade systems. J Clean Prod 234:1033-1044

Ali M, Geng Y, Robins D, Cooper D, Roberts W, Vogtländer J (2019b) Improvement of waste management practices in a fast expanding sub-megacity in Pakistan, on the basis of qualitative and quantitative indicators. Waste Manage 85:253-263

Ali M, Marvuglia A, Geng Y, Chaudhry N, Khokhar S (2018a) Emergy based carbon footprinting of household solid waste management scenarios in Pakistan. Resour Conserv Recycl 131:283-296

Ali T, Irfan M, Alwadie AS, Glowacz A (2020) IoT-based smart waste bin monitoring and municipal solid waste. Arab J Sci Eng 45:10185-10198

Ali Y, Aslam Z, Dar HS, Mumtaz U (2018b) A multi-criteria decision analysis of solid waste treatment options in Pakistan: Lahore City - a case in point. Environment Systems and Decisions 38:528-543

Ali Y, Jokhio DH, Dojki AA, Rehman Ou, Khan F, \& Salman A (2021a) Adoption of circular economy for food waste management in the context of a developing country. Waste Management \& Research. https://doi.org/10.1177/0734242X211038198

Ali Y, Razi M, Felice FD, Sabir M, Petrillo A (2019c) A VIKOR based approach for assessing the social, environmental and economic effects of "smog" on human health. Sci Total Environ 650(2):2897-2905

Ali Z, Mahmood T, Ullah K, Khan Q (2021b) Einstein geometric aggregation operators using a novel complex interval-valued Pythagorean fuzzy setting with application in green supplier chain management. Reports in Mechanical Engineering 2(1):105-134

Alptekin U, Bülent KC, Ayşec T (2020) Location selection for logistics center with fuzzy SWARA and CoCoSo methods. Journal of Intelligent \& Fuzzy Systems 38(4):4693-4709

Appio FP, Lima M, Paroutis S (2019) Understanding smart cities: innovation ecosystems, technological advancements, and societal challenges. Technol Forecast Soc Chang 142:1-14

Asase M, Yanful EK, Mensah M, Stanford J, Amponsah S (2009) Comparison of municipal solid waste management systems in Canada and Ghana: a case study of the cities of London, Ontario, and Kumasi, Ghana. Waste Management 29(10):2779-2786

Ashraf A, Butt A, Khalid I, Alam RU, Ahmad SR (2019) Smog analysis and its effect on reported ocular surface diseases: a case study of 2016 smog event of Lahore. Atmos Environ 198:257-264

Aslam S, Ali F, Naseer A (2021) Application of material flow analysis for the assessment of current municipal solid waste management in Karachi, Pakistan. Waste Management \& Research. https://doi. org/10.1177/0734242X211000427

Awasthi A, Govindan K, Gold S (2018) Multi-tier sustainable global supplier selection using a fuzzy AHP-VIKOR based approach. Int J Prod Econ 195:106-117

Azam M, Jahromy SS, Raza W, Raza N, SooLee S, Kime K-H et al (2020) Status, characterization, and potential utilization of municipal solid waste as renewable energy source: Lahore case study in Pakistan. Environment International 134:105291
Badi I, Pamucar D (2020) Supplier selection for steelmaking company by using combined Grey-MARCOS methods. Decision Making: Applications in Management and Engineering $3(2): 37-48$

Bakır M, Atalık Ö (2021) Application of fuzzy AHP and fuzzy MARCOS approach for the evaluation of e-service quality in the airline industry. Decision Making: Applications in Management and Engineering 4(1):127-152

Baldassarre B, Schepers M, Bocken N, Cuppen E, Korevaar G, Calabretta G (2019) Industrial Symbiosis: towards a design process for eco-industrial clusters by integrating circular economy and industrial ecology perspectives. J Clean Prod 216:446-460

Bao Z, Lu W, Chi B, Yuan H, Hao J (2019) Procurement innovation for a circular economy of construction and demolition waste: lessons learnt from Suzhou, China. Waste Manage 99:12-21

Baset M, Chang V, Gamal A, Smarandache F (2019) An integrated neutrosophic ANP and VIKOR method for achieving sustainable supplier selection: a case study in importing field. Comput Ind 106:94-110

Blaisi NI (2019) Construction and demolition waste management in Saudi Arabia: current practice and roadmap for sustainable management. J Clean Prod 221:167-175

Bui TD, Tsai FM, Tseng LM, Ali MH (2020) Identifying sustainable solid waste management barriers in practice using the fuzzy Delphi method. Resources, Conservation and Recycling 154:104625

Cambier C, Galle W, Temmerman ND (2020) Research and development directions for design support tools for circular building. Buildings 10(8): 142

Cardullo P, Kitchin R (2019a) Being a 'citizen' in the smart city: up and down the scaffold of smart citizen participation in Dublin, Ireland. GeoJournal 84:1-13

Cardullo P, Kitchin R (2019b) Smart urbanism and smart citizenship: the neoliberal logic of 'citizen-focused' smart cities in Europe. Environment and Planning c: Politics and Space 37(5):813-830

Cassady B (2018) Linkdin. https://www.linkedin.com/pulse/worldssimplest-most-cost-effective-solution-garbage-bryancassady/. Accessed 12 Apr 2021

Chang TH (2014) Fuzzy VIKOR method: a case study of the hospital service evaluation in Taiwan. Inf Sci 271:196-212

Covidou E, Velis CA, Purnell P, Zwirner O, Brown A, Hahladakis J et al (2017) Metrics for optimising the multi-dimensional value of resources recovered from waste in a circular economy: a critical review. Journal of Cleaner Production 166:910-938

Devadoss PS, Pariatamby A, Bhatti MS, Chenayah S, Shahul F (2021) Strategies for reducing greenhouse gas emissions from municipal solid waste management in Pakistan. Waste Management \& Research. https://doi.org/10.1177/0734242X20983927

Dipak G, Aithal PS (2021) Smart city waste management through ICT and IoT driven solution. International Journal of Applied Engineering and Management Letters 5(1):51-65

Dolla T, Laishram B (2020) Factors affecting public-private partnership preference in Indian municipal waste sector. Int J Constr Manag 20:567-584

Ellen MacArthur Foundation (2013) Towards the circular economy. [Online] Available at: https://ellenmacarthurfoundation.org/ towards-the-circular-economy-vol-1-an-economic-and-busin ess-rationale-for-an. Accessed 3 Sep 2021

Esmaeilian B, Wang B, Lewis K, Duarte F, Ratti C, Behdad S (2018a) The future of waste management in smart and sustainable cities. Waste Manage 81:177-195

Esmaeilian B, Wang B, Lewis K, Duarte F, Ratti C, Behdad S (2018b) The future of waste management in smart and sustainable cities: a review and concept paper. Waste Manage 81:177-195

Faccio M, Persona A, Zanin G (2011) Waste collection multi objective model with real time traceability data. Waste Manage 31(12):2391-2405 
Farooq S (2018) Smart Cities Context in Pakistan: Case of Lahore and Multan. United Nation University, Lahore

Fatimah YA, Govindan K, Murniningsih R, Setiawan A (2020) Industry 4.0 based sustainable circular economy approach for smart waste management system to achieve sustainable development goals: a case study of Indonesia. Journal of Cleaner Production 269:122263

Ferronato N, Rada EC, Portillo MA, Cioca LI, Ragazzi M, Torretta V (2019) Introduction of the circular economy within developing regions: a comparative analysis of advantages and opportunities for waste valorization. J Environ Manage 230:366-378

Fetanat A, Mofid H, Mehrannia M, Shafipour G (2019) Informing energy justice based decision-making framework for waste-toenergy technologies selection in sustainable waste management: a case of Iran. J Clean Prod 228:1377-1390

Fortunati S, Martiniello L, Morea D (2020) The strategic role of the corporate social responsibility and circular economy in the cosmetic industry. Sustainability 12(12):5120

Gündoğdu FK, Kahraman C, \& Karaşan A (2019) Sphericalfuzzy VIKOR method and its application to waste management. In C. S. Kahraman C. (Ed.), Intelligent and Fuzzy Techniques in Big Data Analytics and Decision Making (pp. 997-1005). Switzerland: Springer, Cham

Hameed HB, Ali Y, Petrillo A (2020) Environmental risk assessment of E-waste in developing countries by using the modified-SIRA method. Science of The Total Environment 733:138525

Hannan M, Arebey M, Begum R, Basri H (2011) Radio Frequency Identification (RFID) and communication technologies for solid waste bin and truck monitoring system. Waste Manage 31(12):2406-2413

Hannan M, Begum R, Shetwi AQ, Ker P, Mamun M, Hussain A et al (2020) Waste collection route optimisation model for linking cost saving and emission reduction to achieve sustainable development goals. Sustainable Cities and Society 62:102393

Hartley K, Santen R, Kirchherr J (2020) Policies for transitioning towards a circular economy: expectations from the European Union (EU). Resources, Conservation and Recycling 155:104634

Haupt M, Hellweg S (2019) Measuring the environmental sustainability of a circular economy. Environmental and Sustainability Indicators 1:100005

Henry M, Schraven D, Bocken N, Frenken K, Hekkert M, Kirchherr J (2021) The battle of the buzzwords: a comparative review of the circular economy and the sharing economy concepts. Environ Innov Soc Trans 38:1-21

Hina SM, Szmerekovsky J, Lee ES, Amin M, Arooj S (2020) Effective municipal solid waste collection using geospatial information systems for transportation: a case study of two metropolitan cities in Pakistan. Research in Transportation Economics 84:100950

Ikram M, Zhou P, Shah S, Liu G (2019) Do environmental management systems help improve corporate sustainable development? Evidence from manufacturing companies in Pakistan. J Clean Prod 226:628-641

Ilyas H, Ilyas S, Ahmad SR, Ch MN (2017) Waste generation rate and composition analysis of solid waste in Gujranwala City Pakistan. International Journal of Waste Resources 7(3):297

International trade administration (2019) Waste Management. https:// www.trade.gov/knowledge-product/pakistan-wastemanagement. Accessed 17 Mar 2021

Jabłoński A, \& Jabłoński M (2020) New economy business models in the concepts of big data, the sharing economy and the circular economy. In Social Business Models in the Digital Economy (pp. 51-88). Palgrave Macmillan, Cham

Keršuliene V, Zavadskas EK, Turskis Z (2010) Selection of rational dispute resolution method by applying new step-wise weight assessment ratio analysis (Swara). J Bus Econ Manag 11(2):243-258
Khan AR, Ditta A, Mehmood MS, Sheng ZM, Natalia M (2021a) Determinants and implications of environmental practices for waste management and the minimization in the construction industry: a case study of Pakistan. Environ Sci Pollut Res 28:58221-58231

Khan F, Ali Y, Khan AU (2020) Sustainable hybrid electric vehicle selection in the context of a developing country. Air Qual Atmos Health 13:489-499

Khan F, Ali Y, Pamucar D (2021) A new fuzzy FUCOM-QFD approach for evaluating strategies to enhance the resilience of the healthcare sector to combat the COVID-19 pandemic. Kybernetes. https://doi.org/10.1108/K-02-2021-0130

Korai MS, Ali M, Lei C, Mahar RB, Yue D (2020) Comparison of MSW management practices in Pakistan and China. J Mater Cycles Waste Manage 22:443-453

Korai MS, Mahar RB, Uqaili MA (2017) The feasibility of municipal solid waste for energy generation and its existing management practices in Pakistan. Renew Sustain Energy Rev 72:338-353

Kumar AAA, Gupta H (2020) Evaluating green performance of the airports using hybrid BWM and VIKOR methodology. Tourism Management 76:103941

Kumar H, Singh MK, Gupta M, Madaan J (2020) Moving towards smart cities: solutions that lead to the Smart City Transformation Framework. Technological Forecasting and Social Change 153:119281

Kumar H, Singh MK, Gupta M, Madaan V (2020) Moving towards smart cities: solutions that lead to the Smart City Transformation Framework. Technological Forecasting and Social Change 153:119281

Lenkiewicz Z (2016) Waste and the Sustainable Development Goals. https://wasteaid.org/waste-sustainable-development-goals/. Accessed 17 Mar 2021

Liu L, Liao W (2021) Optimization and profit distribution in a twoechelon collaborative waste collection routing problem from economic and environmental perspective. Waste Manage 120:400-414

Liu Z, Adams M, Walker TR (2008) Are exports of recyclables from developed to developing countries waste pollution transfer or part of the global circular economy? Resour Conserv Recycl 136:22-23

Lozano Á, Caridad J, Paz JF, González GV, Bajo J (2018) Smart waste collection system with low consumption LoRaWAN nodes and route optimization. Sensors 18(5):1465

Lu X, Pu X, Han X (2020) Sustainable smart waste classification and collection system: a bi-objective modeling and optimization approach. Journal of Cleaner Production 276:124183

Maghsoodi AI, Maghsoodi AI, Mosavi A, Rabczuk T, Zavadskas EK (2018) Renewable energy technology selection problem using integrated H-SWARA-MULTIMOORA approach. Sustainability 10(12):4481

Marshall RE, Farahbakhsh K (2013) Systems approaches to integrated solid waste management in developing countries. Waste Manage 33(4):988-1003

Masood M, Barlow CY, Wilson DC (2014) An assessment of the current municipal solid waste management system in Lahore Pakistan. Waste Management \& Research 32(9):834-847

Meksavang P, Shi H, Lin S-M, Liu H-C (2019) An extended picture fuzzy VIKOR approach for sustainable supplier management and its application in the beef industry. Symmetry 11(4):468

Melaré AV, González SM, Faceli K, Casadei V (2017a) Technologies and decision support systems to aid solid-waste. Waste Manage 59:567-584

Melaré AV, González SM, Faceli K, Casadei V (2017b) Technologies and decision support systems to aid solid-waste management: a systematic review. Waste Manage 59:567-584 
Mi X, Tian Y, Kang B (2021) A hybrid multi-criteria decision making approach for assessing health-care waste management technologies based on soft likelihood function and D-numbers. Appl Intell 5:6708-6727

Mittal AK (2020) Segregation of waste using IOT. International Journal of Advanced Computer Research 8(5):565-567

Muhammad JL, Badi I, Haruna AA, Mohammed AI (2021) Selecting the best municipal solid waste management techniques in Nigeria using multi criteria decision making techniques. Reports in Mechanical Engineering 2(1):180-189

Narayanan A.K, Jinesh N (2018). Application of SWARA and TOPSIS methods for supplier selection in a casting unit. International Journal of Engineering Research \& Technology, 7(5)

Nasir A, Shahzad M, Anwar S, Rashid S (2017) Digital governance: improving solid waste management through ICT reform in Punjab. Association for Computing Machinery, New York

Nathanson J (2020) Solid-waste management. https://www.britannica. com/technology/solid-waste-management. Accessed 16 Mar 2021

Nižetić S, Djilali N, Papadopoulos A, Rodrigues JJ (2019) Smart technologies for promotion of energy efficiency, utilization of sustainable resources and waste management. J Clean Prod 231:565-591

Ong TS, Magsi HB, Burgess TF (2019) Organisational culture, environmental management control systems, environmental performance of Pakistani manufacturing industry. Int J Product Perform Manag 68(7):1293-1322

Opricovic S, Tzeng G-H (2007) Extended VIKOR method in comparison with outranking methods. Eur J Oper Res 178(2):514-529

Papagiannakis G, Voudouris I, Lioukas S, Kassinis G (2019) Environmental management systems and environmental product innovation: the role of stakeholder engagement. Bus Strateg Environ 28(6):939-950

Pardini K, Rodrigues JJ, Diallo O, Das AK, Albuquerque VH, Kozlov SA (2020) A smart waste management solution geared towards citizens. Sensors 20(8):2380

Perçin S (2019) An integrated fuzzy SWARA and fuzzy AD approach for outsourcing provider selection. J Manuf Technol Manag 30(2):531-552

Perey R, Benn S, Agarwal R, Edwards M (2018) The place of waste: changing business value for the circular economy. Bus Strateg Environ 27(5):631-642

Quina MJ, Bontempi E, Bogush A, Schlumberger S, Weibel G, Braga R et al (2018) Technologies for the management of MSW incineration ashes from gas cleaning: new perspectives on recovery of secondary raw materials and circular economy. Sci Total Environ 635:526-542

Ramos TR, Morais CS, Póvoa AP (2018) The smart waste collection routing problem: alternative operational management approaches. Expert Syst Appl 103:146-158

Ranchordás S (2020) Nudging citizens through technology in smart cities. International Review of Law, Computers \& Technology 34(3):254-276

Rani P, Mishra AR, Mardani A, Cavallaro F, Štreimikienė D, Khan SA (2020) Pythagorean fuzzy SWARA-VIKOR framework for performance evaluation of solar panel selection. Sustainability 12(10):4278

Rani P, Mishra AR, Pardasani KR, Mardani A, Liao H, Streimikiene D (2019) A novel VIKOR approach based on entropy and divergence measures of Pythagorean fuzzy sets to evaluate renewable energy technologies in India. Journal of Cleaner Production 238:117936

Rashid A (2020) Corporate social responsibility reporting: meeting stakeholders expectations or efficient allocation of resources? Int J Account Inf Manag 29(2):280-304
Safar KM, Bux MR, Faria U, Pervez S (2021) Integrated model of municipal solid waste management for energy recovery in Pakistan. Energy 219:119632

Salmenperä H, Pitkänen K, Kautto P, Saikku L (2021) Critical factors for enhancing the circular economy in waste management. Journal of Cleaner Production 280:124339

Salmenperä H, Pitkänen K, Kautto P, Saikku L (2021) Critical factors for enhancing the circular economy in waste management. Journal of Cleaner Production 280(1):124339

Sarc R, Curtis A, Kandlbauer L, Khodier K, Lorber K, Pomberger R (2019) Digitalisation and intelligent robotics in value chain of circular economy oriented waste management - a review. Waste Manage 95:476-492

Schwanholz J, Leipold S (2020) Sharing for a circular economy? An analysis of digital sharing platforms' principles and business models. Journal of Cleaner Production 269:122327

Shah SA, Longsheng C, Solangi YA, Ahmad M, Ali S (2021) Energy trilemma based prioritization of waste-to-energy technologies: implications for post-COVID-19 green economic recovery in Pakistan. Journal of Cleaner Production 284:124729

Shah SZ, Nawaz Z, Nawaz S, Carder G, Ali M, Soomro N et al (2019) The role and welfare of cart donkeys used in waste management in Karachi Pakistan. Animals 9(4):159

Sharma M, Joshi S, Kannan D, Govindan K, Singh R, Purohit H (2020) Internet of Things (IoT) adoption barriers of smart cities' waste management: an Indian context. Journal of Cleaner Production 270:122047

Shaukat N, Ullah Z, Khan B, Ali SM, \& Waseem A (2019) "An information-based waste management approach for Pakistan," 2019 International Conference on Electrical, Communication, and Computer Engineering (ICECCE). (pp. 1-5). Swat: IEEE

Shyam GK, Manvi SS, \& Bharti P (2017) Smart waste management using Internet-of-Things (IoT). Chennai, India: IEEE

Škrinjarić T (2020) Empirical assessment of the circular economy of selected European countries. Journal of Cleaner Production 255:120246

Sodhi B, Prabhakar TV (2012) A simplified description of fuzzy TOPSIS. India: Computer Science: Artificial Intelligence. arXiv: 1205.5098

Tariq H, Ali Y, Khan AU, Petrillo A, Felice FD (2021) Sustainable production of diapers and their potential outputs for the Pakistani market in the circular economy perspective. Science of The Total Environment 769:145084

The World Bank (2019) Trends in Solid Waste Management. The World Bank, Washington, D.C

Torkayesh AE, Malmir B, Asadabadi MR (2021) Sustainable waste disposal technology selection: the stratified best-worst multicriteria decision-making method. Waste Manage 122:100-112

Usman M, Yasin H, Nasir A, Mehmood W (2017) A case study of groundwater contaimination due to open dumping of muncipal solid waste in Faisalabad Pakistan. Earth Sciences Pakistan 1(2):15-16

Utrillas MM, Medina MR, Esparza JC, Perello JC (2015) Hybrid method for selection of the optimal process of leachate treatment in waste treatment and valorization plants or landfills. Clean Techn Environ Policy 17:873-885

Vafaeipour M, Zolfani SH, Varzandeh MH, Derakhti A, Eshkalag MK (2014) Assessment of regions priority for implementation of solar projects in Iran: new application of a hybrid multi-criteria decision. Energy Convers Manage 86:653-663

Vanapalli KR, Sharma HB, Ranjan VP, Samal B, Bhattacharya J, Dubey BK et al (2021) Challenges and strategies for effective plastic waste management during and post COVID-19 pandemic. Science of The Total Environment 750:141514

Vesković S, Stević Ž, Stojić G, Vasiljević M, Milinković S (2018) Evaluation of the railway management model by using a new 
integrated model DELPHI-SWARA-MABAC. Decision Making: Applications in Management and Engineering 1(2):34-50

Vohra D, Gunjan, Gandhi A (2020) Incentivized techbin: a step towards sustainable environment. International Journal of Engineering Applied Sciences and Technology 5(2):141-148

Wainaina S, Awasthi MK, Sarsaiya S, Chen H, Singh E, Kumar A et al (2020) Resource recovery and circular economy from organic solid waste using aerobic and anaerobic digestion technologies. Bioresource Technology 301:122778

Wilts H, Garcia BR, Garlito RG, Gómez LS, Prieto EG (2021) Artificial intelligence in the sorting of municipal waste as an enabler of the circular economy. Resources 10(4):28

Yadav G, Mangla SK, Luthra S, Rai DP (2019) Developing a sustainable smart city framework for developing economies: an Indian context. Sustainable Cities and Society 47:101462

Yong R (2007) The circular economy in China. J Mater Cycles Waste Manag 9:121-129

Yong YS, Lim YA, Ilankoon I (2019) An analysis of electronic waste management strategies and recycling operations in Malaysia: challenges and future prospects. J Clean Prod 224:151-166

Yuan J, Li X, Ke Y, Xu W, Xu Z, Skibniewski MJ (2020) Developing a building information modeling-based performance management system for public-private partnerships. Eng Constr Archit Manag 27(8):1727-1762

Zadeh L (1965) Fuzzy sets. Inf Control 8(3):338-353
Zarbakhshnia N, Soleimani H, Ghaderi H (2018) Sustainable thirdparty reverse logistics provider evaluation and selection using fuzzy SWARA and developed fuzzy COPRAS in the presence of risk criteria. Appl Soft Comput 65:307-319

Zhang A, Venkatesh V, Liu Y, Wan M, Qu T, Huisingh D (2019) Barriers to smart waste management for a circular economy in China. Journal of Cleaner Production 240:118198

Zhang D (2019) Application of blockchain technology in incentivizing efficient use of rural wastes: a case study on Yitong system. Energy Procedia 158:6707-6714

Zolfani SH, Saparauskas J (2013) New application of SWARA method in prioritizing sustainability assessment indicators of energy system. ECONOMICS OF ENGINEERING DECISIONS 24(5):66-153

Zolfani SH, Chatterjee P (2019) Comparative evaluation of sustainable design based on step-wise weight assessment ratio analysis (SWARA) and Best Worst Method (BWM) Methods: a perspective on household furnishing materials. Symmetry 11(1):74

Zolnikov TR, Silva RC, Tuesta AA, Marques CP, Cruvinel VR (2018) Ineffective waste site closures in Brazil: a systematic review on continuing health conditions and occupational hazards of waste collectors. Waste Manage 80:26-39

Publisher's Note Springer Nature remains neutral with regard to jurisdictional claims in published maps and institutional affiliations. 